\title{
COMMUNITY SOCIAL AND
} PLACE PREDICTORS OF SENSE OF COMMUNITY: A MULTILEVEL AND LONGITUDINAL ANALYSIS

\section{Adam Long}

Gordian Health Solutions, Inc.

Douglas D. Perkins

Vanderbilt University

\begin{abstract}
Sense of community (SOC) is empirically "unpacked" as a multilevel construct with place and social elements. SOC has been studied primarily at the individual level despite researchers acknowledging its effects at the community level. Little attention has been given to the roles of place and place attitudes in SOC. We argue that place and social are inextricably bound, and studying the impact of the social alone on community-oriented constructs like SOC constrains our ability to adequately understand such multilevel, multifaceted phenomena. The present, cross-sectional and longitudinal analyses demonstrate that SOC is intimately related to social capital (neighboring, citizen participation, collective efficacy, informal social control), communitarianism, place attachment, community confidence, and community satisfaction. Implications for community and environmental psychology theory are discussed. (C) 2007 Wiley Periodicals, Inc.
\end{abstract}

Sense of community (SOC) has been a vitally important concept in community psychology since it was first defined (Sarason, 1974), then refined (McMillan \& Chavis, 1986) and studied extensively, as reported in part in four special issues of the Journal of Community Psychology and, most recently, an edited volume (Fisher, Sonn, \& Bishop, 2002). SOC has also reached into the interdisciplinary realm in its tie to social capital (Perkins, Hughey, \& Speer, 2002). As "the norms, networks, and mutual trust of "civil society' facilitating cooperative action among citizens and institutions" (Perkins \& Long, 2002, p. 291), social capital is argued to be intricately tied to SOC. All this is despite the fact that SOC has been a rather difficult construct to define, some even

Correspondence to: Douglas D. Perkins, Department of Human and Organizational Development, Box 90, Peabody College, Vanderbilt University, Nashville, TN 37203-5701. E-mail: doug.perkins@vanderbilt.edu 
suggesting it has "become stuck at the stage of construct definition and measurement" (Chavis \& Pretty, 1999, p. 645).

In spite of such problems of definition, SOC has become a highly influential construct, assisting in our understanding of varied phenomena across different populations and environments (e.g., workplaces, online groups, colleges, substance abuse programs, religious and residential communities). It has also been studied crossculturally in its relation to such things as common land use, participation in community groups, social climate, and loneliness. In much of this research, SOC is assumed to be both an individual-level and a group-level phenomenon, but most investigators have studied it only at the individual level of analysis. Some have examined it at the group level (Buckner, 1988; Fisher et al., 2002; Kingston, Mitchell, Florin, \& Stevenson, 1999; Long \& Perkins, 2003; Perkins, Brown, \& Taylor, 1996; Perkins, Florin, Rich, Wandersman, \& Chavis, 1990; Sampson, 1991). A few have used it in multilevel analyses (Brodsky, O'Campo, \& Aronson, 1999; Hyde, 1998; Kingston et al., 1999; Sampson), but none of those analyzed SOC simultaneously at both the individual and the group levels, which is surprising given the construct's implied validity and relevance across multiple levels. Perkins and Long (2002) did analyze SOC at multiple levels simultaneously and found that SOC operates differently at individual and community levels to predict informal neighboring behavior, formal citizen participation, and informal collective efficacy/empowerment (by their definition, the other three dimensions of social capital).

We have three main goals for this article. The first is to provide further construct validity to SOC by applying multilevel analyses to the longitudinal prediction of individual SOC. SOC operates simultaneously at both group/community and individual levels, but how do multilevel community-focused cognitions and behaviors (the other three social capital dimensions) relate to SOC? Our second goal is thus to address further the validity of this four-dimensional structure of social capital, thereby introducing more community psychologists to social capital and, in turn, informing researchers and program planners in social services, community development, and urban policy that many concepts thoroughly studied by community psychologists have real world application. Our third goal is to address empirically the effects of multilevel place-based attitudes on SOC. Environmental social psychologists have argued for some time that aspects of the social are inextricably bound to the places in which they are enacted (e.g., Proshansky, Fabian, \& Kaminoff, 1983). If bound in this manner, individual attitudes and the social climate specific to the relevant ecological niche should show significant effects on the cognitive-perceptual construct that is SOC. Figure 1 roughly models the relations between these multilevel place and social (capital) constructs on SOC. ${ }^{1}$

\section{SOCIAL CAPITAL AND OTHER SOGIAL AND PLACE PREDICTORS OF SENSE OF COMMUNITY}

Perkins and Long (2002) have made the case and showed evidence that SOC should be considered as one of four dimensions of social capital, including collective efficacy,

\footnotetext{
${ }^{1}$ Figure 1 is not intended to be exhaustive of those multilevel aspects of the place and social milieu that affect SOC, nor do we mean to suggest a firm causal order of relations among these constructs. Rather, the diagram is presented as a conceptual aid, putting a graphical face to the relations of empirical interest.
} 


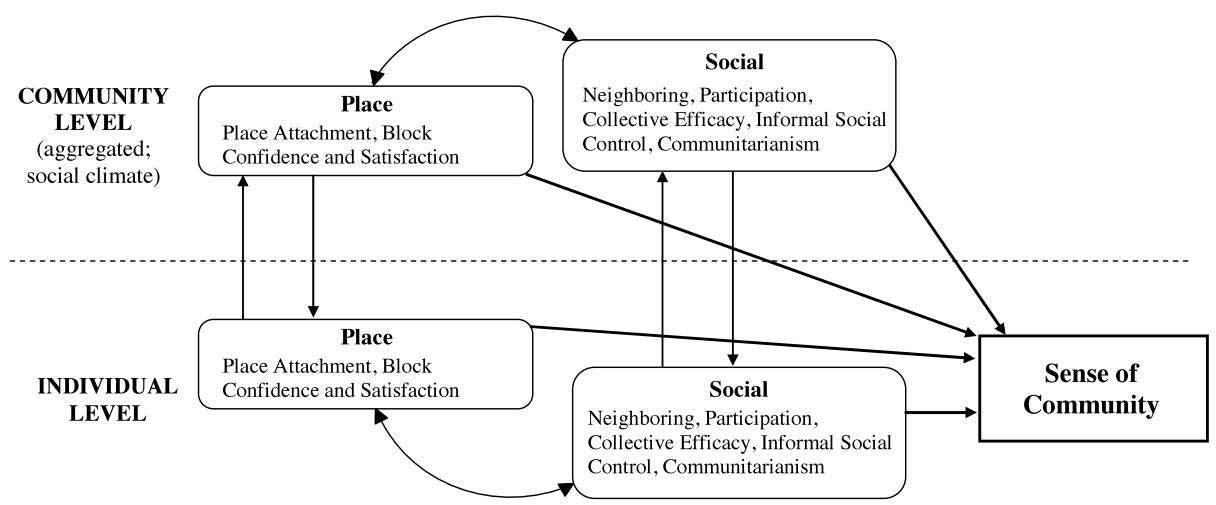

Figure 1. Conceptual and Methodological Representation of Community Social and Place Predictors of Sense of Community.

neighboring behavior, and formal citizen participation. Also, in multilevel crosssectional analyses of several community-focused cognitions, SOC at both levels of analysis was shown to be unsurpassed as a predictor of the other three dimensions of social capital. Specifically, SOC was the only group- and individual-level predictor, including demographics, that was significant in all analytic models. That is to say, either living on a block with higher mean SOC or having higher individual SOC (relative to neighbors) was related to higher collective efficacy, more neighboring behaviors, and more participation in civic organizations.

Social capital is closely related to SOC. Contrary to SOC, however, social capital has more often been conceptualized as operating at the group/community level. Research into the interplay between SOC and social capital is needed to understand how they relate to one another: Do they operate independently, additively, within a nested structure, or another relation altogether? And because Perkins and Long (2002) studied collective efficacy (empowerment), neighboring, and participation only at the individual level of analysis, it is necessary to begin to study these components of social capital at multiple levels.

Neighboring behavior is "informal mutual assistance and information sharing among neighbors" (Perkins \& Long, 2002, p. 295), which may consist of instrumental or noninstrumental social support/contact (Unger \& Wandersman, 1985). Several researchers have found ties between SOC and neighboring behavior but most were correlational/ cross-sectional. Several (Brown \& Werner, 1985; Chavis \& Wandersman, 1990; Hughey, Speer, \& Peterson, 1999) have found a positive correlation between SOC and neighboring behavior; the same relation is also seen at the street block level (Perkins \& Long, 2002). Further, Wandersman and Giamartino (1980) found that participants of block associations reported more SOC and neighboring behavior than nonparticipants. Others have shown that neighboring predicts SOC in cross-sectional regression analyses (Prezza, Amici, Roberti, \& Tedeschi 2001), but none to our knowledge have shown lagged or time-change effects of neighboring on SOC or, for that matter, the effect of multiple levels of neighboring on SOC simultaneously.

Citizen participation in any grassroots community organization (e.g., block or tenant associations, faith- or school-based coalitions) constitutes formal civic action deemed a prototypical social capital behavior. Not surprisingly, when neighboring and civic participation have been studied conjointly, they are found to relate to SOC in much 
the same way (Chavis \& Wandersman, 1990; Hughey et al., 1999; Itzhaky \& York, 2000; Perkins \& Long, 2002), probably because participation-though formally organized-is a socially interactive behavior as is neighboring. Chavis and Wandersman also showed a lagged effect of participation on SOC. Brodsky et al. (1999), however, appear to be the only ones thus far to use multilevel modeling to predict SOC using civic participation, finding that "neighborhood organizational involvement" at both individual and community levels predicted higher SOC. Adding to Brodsky et al.'s results (but using SOC to predict participation), Perkins and Long (2002) found cross-level interactional effects: SOC and participation were most closely linked on blocks with more children, more educated residents, more long-term residents, and (surprisingly) those with low communitarianism (defined below). We hope to replicate Brodsky et al.'s findings here, but we also demonstrate that such multilevel effects can be shown over time.

Collective efficacy, or trust in the effectiveness of civic action, is similar to the concept of empowerment. It is different from self-efficacy or locus of control because of its tie to collective action and empowerment. Unlike Sampson, Raudenbush, and Earls (1997), however, we do not define collective efficacy as simply the combination of SOC and informal social control (ISC). Collective efficacy is "an appraisal of group behavior that is, as the term suggests, both collectively organized and efficacious" (Perkins \& Long, 2002, p. 295), while ISC is not organized, and helps to reduce crime unpredictably (Perkins, Wandersman, Rich, \& Taylor, 1993). SOC, at both individual and community levels, has been shown to significantly predict individual-level perceptions of collective efficacy in community action (Perkins \& Long).

Informal social control (ISC) is the day-to-day regulation of group/community norms of behavior by members/residents. It may take the form of confronting troublemakers directly or contacting government officials or group/community leaders about problems. Perkins et al. (1990) reported significant positive correlations (partial and zeroorder) at the community level between SOC and ISC. This relation is also noted at the individual level: Speer (2000) found a positive correlation between SOC and personal sense of "interactional control," and Chavis and Wandersman (1990) found a similar relation between SOC and "personal power." The relation between SOC and ISC, having been studied at either level of analysis alone, leaves an important gap in the literature (of both constructs) that may be filled here via multilevel and longitudinal analyses.

Communitarianism is used here as the worth given to community as well as commitment to collective community improvement (Perkins et al., 1990). A communitarian climate, presumably fostered by participation in, neighboring among, and attachment to valued communities, should likewise produce greater SOC. Perkins and Long (2002) found a significant positive relation between SOC and communitarianism at the individual level of analysis, but at the community level this relation was shown at one time point but not another.

Place attachment has been defined variously as "affective ties with the material environment ... [including] fondness for place because it evokes pride" (Tuan, 1974, p. 93, 247); "individuals' commitment to their neighborhood and their neighbors" (Fischer, 1977, p. 139); and "a multilevel person-place bond that evolves from specifiable conditions of place and characteristics of people" (Shumaker \& Taylor, 1983, p. 223). Such place-based emotional bonds are essential to personal and social/ community facets of identity and afford a basis of change as well as stability for individuals and groups/communities alike. 
Theory would thus suggest place attachment and SOC are closely linked. Indeed, the Sense of Community Index (SCI; Perkins et al., 1990) includes four items measuring, we argue, place attachment (in this case, attachment to one's residential block). ${ }^{2}$ Like Puddifoot (1996) and Pretty (2002), who conceptualize SOC and place attachment as components of overarching constructs ("community identity" or "self-incommunity"), we would argue that they are related but separate phenomena.

We view place attachment as distinct from SOC because the former is a spatially oriented emotional construct (Brown \& Perkins, 1992) and the latter is more of a socially oriented cognitive construct. Furthermore, keeping the concepts separate allows us to consider how one may lead to the other or whether different community changes might affect place and social attachments differently. (Perkins \& Long, 2002, p. 297)

Empirical work also suggests a strong relation between place attachment and SOC. Korpela (1989), for example, showed that favorite places sometimes aid in self-esteem maintenance through facilitation of "togetherness." Others have shown that failure to attach to place of residence is associated with less sense of neighborhood community (DeLisi \& Regoli, 2000), e.g., "the people and the facilities did not represent their values and aspirations" (Twigger-Ross \& Uzzell, 1996, p. 218). Still others (Gotham, 1999; Puddifoot, 1997; Taylor, 1996) have found that when a valued place is threatened it can be a strong catalyst for drawing members of the community together (literally and psychologically) to combat the shared threat.

Given that the variable measuring place attachment derived from a scale designed to measure SOC, we were not surprised to learn that Perkins and Long (2002) found high positive correlations among the two constructs with group-level correlations exceeding those at the individual level.

Block satisfaction is related to place attachment, but they are not one in the same. For example, Perkins, et al. (1990) found that residents who had high street block neighborhood place attachment were mixed in their level of satisfaction because, it seems, in some cases they cared about it so much that they also were the most critical when neighborhood problems arose. Hence, place attachment and block satisfaction may relate to SOC in substantively different ways. Block satisfaction is, however, generally positively related with SOC (Chavis \& Wandersman, 1990; Perkins et al., 1990; Sampson, 1991); in each case, the effect was demonstrated at both levels of analysis, although none studied multilevel effects over time.

Block confidence, or residents' confidence in the future of their street block neighborhood, is another important cognition related to SOC. Ahlbrandt (1984) and Varady (1986) have argued that, particularly in declining or transitional neighborhoods, individual and collective confidence in the viability of the social and place community can have wide-ranging implications for economic and emotional (dis)investment by residents. For example, a neighborhood perceived to be in decline with little hope for revitalization may prompt little individual or collective efforts at physical or social improvements. Such social disinvestment parallels social identity theory (Tajfel \& Turner, 1979 ) in that one may refuse to identify with an in-group that no longer meets one's expectations. Thus, community confidence should directly relate to SOC at both individual and community levels. Varady (1986) and Perkins and Long (2002) did

\footnotetext{
${ }^{2}$ For the present analyses, as elsewhere (Perkins \& Long, 2002), these four items were used as a measure of place attachment separate from SOC.
} 
indeed find that block confidence is related to SOC at both levels of analysis. The question, as before, is whether such multilevel effects are also significant when considering changes over time. Unlike the other community-focused predictors described above, confidence is intimately tied to perceptions of the future. Hence, whether and/or how multilevel community confidence predicts SOC over time could have broad implications for researchers in basic and applied fields of study.

Demographics have been studied with SOC since the beginning, producing a few reliable results across various SOC measurement methodologies. At the individual level, SOC is often greater in females (Brodsky et al., 1999; Long \& Perkins, 2003) and those who are married (Buckner, 1988; Prezza et al., 2001), and increases with age (Brodsky et al., 1999; Buckner; Perkins \& Long, 2002; Prezza et al.), children in the home (Brodsky et al.; Prezza et al.), home ownership (Buckner; Perkins \& Long), tenure within the group/community (Brodsky et al.; Perkins \& Long; Prezza et al.), and income (Kingston et al., 1999; Perkins \& Long). At the group/community level, aggregate SOC has been found to increase with average tenure in the community (Perkins et al.; Perkins \& Long) and proportion home ownership (Brodsky et al.; Perkins et al.; Perkins \& Long) and decrease with greater proportion minority (Brodsky et al.; Perkins et al.) and average household size (Brodsky et al.). However, as Hill (1996) has noted, SOC is context specific, i.e., the relation between it and some sociodemographics can vary widely depending on the particular physical and social environment. For example, at the individual level, number of children in the home is typically associated with more SOC, but Brodsky (1996) has noted a negative relation with mothers in low-income, urban neighborhoods in which they feel the need to protect their children from negative influences. Likewise, contrary results have been found for individual-level education and minority status, with some finding positive and some negative relations to SOC (see Brodsky et al.; Buckner; Kingston et al., 1999; Long \& Perkins). At the group/community-level, average income has similarly been related to both higher (Perkins et al.) and lower (Brodsky et al.) SOC.

\section{Human Capital and Social Capital in Interaction}

Taking Hill's (1996) argument a bit further, we may speculate that SOC may result from an interaction of individual and collective resources (i.e., human and social capital). Perceptions of group cohesion may thus derive, for example, from a combination of personal education and social capital resources (collective efficacy, neighboring, participation). The interaction effect could conceivably happen either intrapersonally (e.g., individual participation in combination with individually achieved education) or as a cross-level interaction evident only in multilevel analyses (e.g., individual education in interaction with group level collective efficacy). These interactions will be tested in an exploratory manner.

\section{METHOD}

Data used in analyses come from the New York City Block Booster Project. This clustered resident survey data from the 1985-86 longitudinal study (Perkins et al., 1990) of 47 blocks in five neighborhoods in Brooklyn and Queens permit comparisons over two points in time $(1985, \mathrm{~T} 1 N=1,081 ; 1986$, T2 $N=638$; household panel = 438) using multilevel analysis (HLM) of the constructs as both individual psychological and community climate phenomena. 


\section{Block Booster Project}

Site selection. Three neighborhoods in NYC were first selected based on four criteria: (a) increasing burglary and robbery rates in 1984 (compared to decreasing rates generally throughout the city), (b) those having block associations (BA) within the neighborhood active for at least one year, (c) BA leaders who expressed interest and willingness to participate in an intervention targeted at the block level, and (d) variability across neighborhoods in racial mixture. Blocks $(N=48)$ from the three neighborhoods were then selected using four criteria: (a) mostly residential (e.g., nonresidential properties allowed only on street corners); (b) moderate size (e.g., 25-100 addresses), (c) the block's land use was representative of the neighborhood, and (d) organized and nonorganized blocks sufficiently far apart (to avoid intervention "spill-over" effects; Bennett \& Lavrakas, 1988). Residences were most often single-family homes, duplexes, or small apartment buildings (e.g., 4-10 units).

Data sources. The Project collected data using several sources: (a) telephone survey of block residents, randomly selected within block; (b) survey of block association members; (c) interviews with BA leaders; (d) observational, block environmental inventory; and (e) police records. Only data from the telephone survey is used in the present analyses.

Telephone survey sample and procedure (Perkins et al., 1990). Names, addresses, and phone numbers were selected at random from sampled blocks using a "criss-cross" directory. Data were collected during a 5-week period during the spring of 1985 (Time 1). By accident, one selected block was excluded from the survey, thus making the potential sample 47 blocks with 2,794 residents, 909 of whom could not be contacted and 9 others were excluded due to incompletion or duplication. Of the 1,876 potential subjects, $58 \%$ or 1,081 completed the telephone survey.

Of this T1 sample, 327 (30\%) were active BA members (of 31 different BAs), 422 $(39 \%)$ were inactive or nonmembers of their local BA, $265(25 \%)$ lived on the 13 nonorganized blocks, and the remaining 67 (6\%) lived on three blocks with BAs that, only after sampling, were determined to be inactive or just developing. There were no statistically significant demographic differences between respondents living on organized versus non-organized blocks. The mean number of sampled residents per block was 24, ranging from 10 to 41 . Respondents were $65 \%$ female; $47 \%$ white, $47 \%$ black, and the rest divided among Hispanic, Asian, and "other" ethnicity. About $40 \%$ of the renters lived in homes and the rest lived in apartment buildings. Respondents with high school or less education comprised $42 \%$ of the sample and $29 \%$ were college graduates. All adult age categories were roughly evenly represented in the sample, with a mean age of 42 years. Estimated median sampled household income was $\$ 19,000$; median length of residence was 9.5 years.

The Time 2 data (1 year later; 1986) collected under the same project included some new households and additional blocks. Despite efforts to obtain a respondentlevel panel sample, there was considerable change from T1 to T2. There are several reasons for this problem: residential mobility, respondent refusals at T2, withinhousehold replacements, and attempts to increase the T2 sample. Hence, a respondentlevel longitudinal analysis is not defensible. However, because block-level measures used here are social climate predictors, the full contingent of data available for block aggregation was employed, which allows for the examination of block-level longitudinal 
effects on individual-level SOC. As a result, block-level T1 and change variables represent sampled blocks at different time points but not necessarily the same individuals to represent those blocks at each time.

\section{Instruments}

Data specific to community-focused attitudes and behaviors were used in the present analyses, including the four dimensions of social capital (see Perkins et al., 2002; Perkins \& Long, 2002): sense of community, collective efficacy/empowerment, participation, and neighboring.

Brief Sense of Community Index (BSCI) is a newly developed and validated eight-item scale (see Table 1; Long \& Perkins, 2003), derived partly from the 12-item SCI (Perkins et al., 1990). Due to low subscale internal reliability, only the BSCI was used here (not its subscales).

Participation in block association activities $(\alpha=.78, \mathrm{n}=384 ; .80, \mathrm{n}=184)$ is the sum of eight items coded zero to one (seven items were yes/no and one was recoded to a $0-1$ scale): (a) membership and participation in a BA; (b) whether the respondent had attended, spoken in, served as member or officer in a BA meeting or had done work for the organization outside a meeting in the past year; and (c) monthly hours working for the BA outside of meetings $(1=8$ or more).

Neighboring behavior $(\alpha=.78, \mathrm{n}=1,037 ; .77, \mathrm{n}=615)$ is the mean of five items measuring how many neighbors (none, one-or-two, several) asked the following of respondents: (a) to watch their home while they were away, (b) to loan food or a tool,

Table 1. Brief Sense of Community Index (BSCI; Long Ẽ Perkins, 2003):

Scale $\alpha=.65(T 1), .74$ (T2)

Social Connections Subscale: $\alpha=.55$ (T1), .50 (T2)

Instructions for items 1-5: "I am going to read some things that people might say about their block. For each one, please indicate whether it is mostly true or mostly false about your block" (coded $1=$ "false", $2=$ "true"; Note: Likert scale recommended for future research).

1. Very few of my neighbors know me. (Reverse)

2. I have almost no influence over what this block is like. (Reverse)

3. I can recognize most of the people who live on my block.

Mutual Concern Subscale: $\alpha=.50$ (T1), .64 (T2)

4. My neighbors and I want the same things from the block.

5. If there is a problem on this block people who live here can get it solved.

6. In general, would you say that people on your block watch after each other and help out when they can, or do they pretty much go their own way? (coded 1 = "go own way", 2 = "a little of both", $3=$ "watch after")

Community Values Subscale (Face-valid SOC): $\alpha=.51$ (T1), .61 (T2)

7. Would you say that it is very important, somewhat important or not important to you to feel a sense of community with the people on your block? (coded 1= "not", $2=$ "somewhat", 3 = "very")

8. Some people say they feel like they have a sense of community with the people on their block; others don't feel that way. How about you; would you say that you feel a strong sense of community with others on your block, very little sense of community or something in between? (coded 1 = "very little", 2 = "in between", 3 = "strong")

Note. It was recommended that future uses of the BSCI employ 5-point or 7-point response options to increase variability, sensitivity, and internal reliability (Long \& Perkins, 2003). 
(c) to help in an emergency, (d) to offer advice on a personal problem, and (e) to discuss a block problem.

Collective efficacy $(\alpha=.82, \mathrm{n}=918 ; .82, \mathrm{n}=270)$ is the mean of six items: (a) whether it is likely their block association (or a hypothetical association on unorganized blocks) can accomplish improvement of physical conditions ( not likely, somewhat likely, or very likely); (b) the persuasion of city officials to provide better services; (c) getting people on the block to help each other more; (d) a reduction in crime; (e) getting people to know each other better; and (f) getting information to residents about where to go for needed services.

Informal social control $(\alpha=.56, \mathrm{n}=858 ; .75, \mathrm{n}=574)$ is the mean of three dichotomous items, each with likely/unlikely response options: (a) If someone on the block was letting trash pile up in their yard or on their steps, how likely is it that a neighbor would go to that person and ask that they clean up? (b) If some 10- to 12-year-old kids were spray-painting the sidewalk on the block, how likely is it that some of the neighbors would tell them to stop? (c) If a suspicious stranger was hanging around the block, how likely is it that some of the neighbors would notice this and warn others to be on guard?

Communitarianism is the mean of two items: (a) the importance to the respondent of what their block is like and (b) the importance of neighbors working together rather than alone to improve block conditions (not important, somewhat important, very important).

Place attachment $(\alpha=.65, \mathrm{n}=903 ; .63, \mathrm{n}=480)$ is the mean of four $\mathrm{T} / \mathrm{F}$ items taken from the original SCI: (a) I think my block is a good place for me to live; (b) I feel at home on this block; (c) It is very important to me to live on this particular block; (d) I expect to live on this block for a long time.

Block satisfaction is the mean of two items: (a) satisfaction with the block as a place to live (satisfied/dissatisfied) and (b) compared to adjacent blocks, this block is a better or worse place to live or about the same as other blocks in the area.

Block confidence is the mean of two items: (a) In the past two years, have the general conditions on your block gotten worse, stayed about the same, or improved? (b) In the next two years, do you feel that general conditions on your block will get worse, stay about the same, or improve?

Demographics. The present analyses included the sociodemographic variables income level, education, sex (female), age, race (nonwhite), length of residence, home ownership, and number of children in household.

\section{Strategy of Analysis}

Multilevel modeling is the proper technique for understanding how SOC relates to both individual- and block-level (social climate) phenomena. Hierarchical linear modeling (HLM) software is used. Residents within the same residential block are likely to share similar perceptions, resources, and attitudes because they are nested within the same physically bounded environment. If residents are attracted to specific blocks or if blocks develop in ways that create discrete subcultures, then the "embeddedness" of residents in their block must be taken into account statistically, which is possible with HLM.

Further, HLM can reveal the degree to which the variability in perceptions of SOC is evident at the individual level versus the block level. Many HLM analyses find that 
social phenomena are weighted more toward individual than group sources of variability. This is also the case in these analyses, although a significant part of the total variability in perceptions of SOC is between blocks (5-8\%). Strictly speaking, for an HLM analysis to be deemed necessary, there should be significant variability in the outcome by group (in this case block community). This is tested via an unconditional, one-way ANOVA model, which essentially addresses the question, "Given the small scale of the residential block, and the fact that the adjacent neighborhoods were chosen to be demographically similar, do blocks significantly vary in address-level SOC?" The intraclass correlation coefficient, which is computed from the variance components of this unconditional model, also provides the percentage of variance in the outcome (SOC) that is due to differences between blocks (in this case 5-8\%).

Bryk and Raudenbush (1992) contend that, in HLM, the number of predictors should be restricted due to model fit and sample size limitations. In many cases, this results in testing a select few predictors as well as removing nonsignificant predictors to maximize statistical power. We test more than a few predictors here and thus addressed Bryk and Raudenbush's recommendation by adding clusters of predictors in a stepwise manner, removing nonsignificant predictors (at $p<.10$ at the block level and $\mathrm{p}<.05$ at the individual level) before adding the next cluster to the model. For example, following the unconditional model, we add (a) the individual/householdlevel demographics including age, income, home ownership, education, white ethnicity, sex, number of kids, and length of residence (uncentered and fixed, i.e., not allowing slopes to vary across blocks); (b) then block-level demographics (grand mean centered); (c) then individual/household-level community predictors (uncentered and fixed); and (d) then block-level community predictors (grand mean centered). The only exception to the centering rules outlined above is when the block-aggregated counterpart to an individual-level predictor is in the model at the same time. To avoid shared variance across levels in this instance the individual-level predictor is centered at the block mean.

The resultant trimmed model with predictors at both levels is the full fixed model. The full fixed model is often the most parsimonious model to report. However, before settling on a final model, we test for significant random variance (i.e., allowing slopes to vary across blocks) in individual-level community predictors in the full fixed model one at a time. If an individual-level predictor is found to have significant random variance, exploratory cross-level interaction effects are tested to attempt to explain the significant random variation. As is the case with any regression analysis, block-level main effect counterparts to cross-level interaction terms are added (if not already in the model). The HLM analyses used full maximum likelihood estimation (to test for model fit improvements) and listwise deletion of missing values.

All these variables are from $\mathrm{T} 1$ in the first, cross-sectional analysis. For the second, time change analysis, individual-level T2 BSCI is the outcome. As noted above, it was only possible to test $\mathrm{T} 1$ and time change predictors at the block level. Thus, blocklevel predictors consist of $\mathrm{T} 1$ as well as T1-T2 change predictors (standardized residuals from linear regressions, i.e., unexpected deviation-positive or negative-from the score predicted by the block's T1 value), but individual-level predictors are T2 only. ${ }^{3}$

\footnotetext{
${ }^{3}$ It is unnecessary to include the T1 counterpart to a time change predictor as a control because the two variables are orthogonal.
} 


\section{RESULTS}

\section{Hierarchical Linear Models}

Predicting Time 1 BSCI. In the cross-sectional HLM predicting T1 BSCI (see Table 2), $5.6 \%$ of the total variance is due to differences between blocks $\left(X^{2}(46)=84.99, p=\right.$ .001). At the block level, collective efficacy, civic participation, neighboring, and place attachment were all positively related to resident SOC. At the individual level, length of residence, participation, neighboring, empowerment (i.e., collective efficacy and informal social control), communitarianism, place attachment, block satisfaction and block confidence were all positive predictors of individual SOC. Although all these individual level effects were significant at $p<.05$ (most at $p \leq .002$ ), the greatest effect sizes were for place attachment and neighboring ( $t$-ratios $=8.46$ and 8.43 , respectively). Checking individual-level predictors one at a time for random variance showed no significant effects. The final model explains $39 \%$ of individual-level variance and over $99 \%$ of the block-level variance in T1 BSCI.

Table 2. Hierarchical Linear Model Predicting Time 1 Brief Sense of Community Index, Final Estimation of Fixed Effects (With Robust Standard Errors)

\begin{tabular}{|c|c|c|c|c|c|}
\hline Fixed effect & Coeff. & $S E$ & T-ratio & $d f$ & p-value \\
\hline Block level: intercept & 1.649 & 0.020 & 81.93 & 42 & .000 \\
\hline Collective efficacy & 0.089 & 0.036 & 2.44 & 42 & .019 \\
\hline Participation & 0.023 & 0.014 & 1.70 & 42 & .097 \\
\hline Neighboring & 0.057 & 0.029 & 1.96 & 42 & .057 \\
\hline Place attachment & 0.127 & 0.039 & 3.24 & 42 & .003 \\
\hline \multicolumn{6}{|l|}{ Individual level: } \\
\hline Length of residence & 0.023 & 0.006 & 3.77 & 823 & .000 \\
\hline Informal social control & 0.050 & 0.011 & 4.58 & 823 & .000 \\
\hline Collective efficacy & 0.040 & 0.010 & 3.83 & 823 & .000 \\
\hline Participation & 0.026 & 0.008 & 3.51 & 823 & .001 \\
\hline Neighboring & 0.059 & 0.007 & 8.43 & 823 & .000 \\
\hline Communitarianism & 0.035 & 0.008 & 4.15 & 823 & .000 \\
\hline Block satisfaction & 0.017 & 0.008 & 2.18 & 823 & .029 \\
\hline Block confidence & 0.020 & 0.006 & 3.17 & 823 & .002 \\
\hline Place attachment & 0.076 & 0.009 & 8.46 & 823 & .000 \\
\hline
\end{tabular}

Final estimation of variance components:

\begin{tabular}{lccccc} 
Random effect & $S D$ & Var. Component & $d f$ & Chi-square & $p$-value \\
\hline INTRCPT, U0 & 0.004 & 0.000 & 42 & 44.66 & .36 \\
Level-1, R & 0.170 & 0.029 & & &
\end{tabular}

Level 2 Intraclass $r=.0557, p=.001$, (or $5.57 \%$ of total variance in DV is due to differences between blocks). Model explains $39.1 \%$ of Level 1 (individual) variance, and $99.6 \%$ of Level 2 (block) variance.

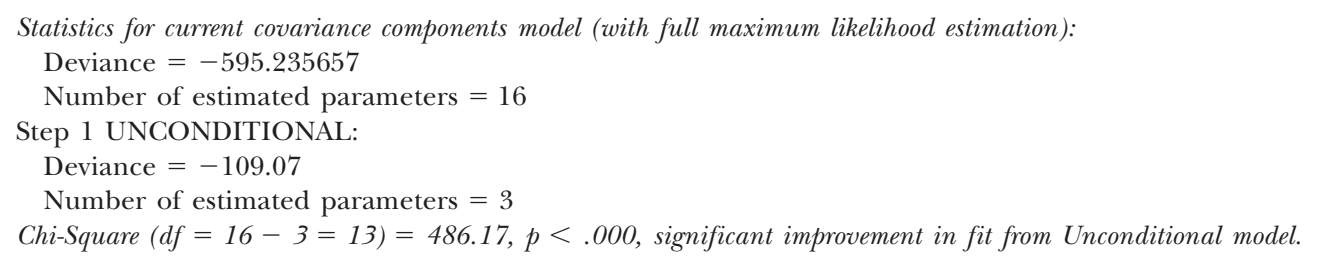


Predicting Time 2 BSCI. In the HLM predicting T2 BSCI (see Table 3), 8.1\% of the total variance is due to block differences $\left(X^{2}(43)=80.85, p=.001\right)$. At the block level, T1 informal social control, and residualized change in civic participation and place attachment were positive and significant predictors of T2 BSCI. Specifically, higher levels of block mean informal social control at T1 predicted greater respondent SOC at T2, and increasing block mean citizen participation and place attachment predicted greater respondent SOC at T2. At the individual level, T2 informal social control, neighboring, participation, communitarianism, place attachment, and block satisfaction were significant, positive predictors of T2 BSCI. The only individual-level predictor to show significant random variance was T2 place attachment. Block-level income and nonwhite status were the only predictors found to interact significantly with T2 place attachment, which together did not explain all significant random variance in T2 place attachment. The final model (displayed in Table 3) explains over $39 \%$ of individuallevel variance and over $68 \%$ of block-level variance in T2 BSCI.

Table 3. Hierarchical Linear Model Predicting Time 2 Brief Sense of Community Index (BSCI) Using Lagged and Time-Change Block-Level Predictors and Time 2 Individual-Level Predictors, Final Estimation of Fixed Effects (With Robust Standard Errors)

\begin{tabular}{|c|c|c|c|c|c|}
\hline Fixed effect & Coeff. & $S E$ & T-ratio & $d f$ & p-value \\
\hline Block level: intercept & 1.766 & 0.009 & 191.00 & 38 & .000 \\
\hline T1 Nonwhite & 0.016 & 0.030 & 0.53 & 38 & .600 \\
\hline $\mathrm{T} 1$ Income & 0.028 & 0.026 & 1.06 & 38 & .297 \\
\hline T1 Informal social control & 0.224 & 0.088 & 2.54 & 38 & .016 \\
\hline Time $1-2$ participation & 0.035 & 0.008 & 4.41 & 38 & .000 \\
\hline Time $1-2$ place attachment & 0.026 & 0.007 & 3.83 & 38 & .001 \\
\hline \multicolumn{6}{|l|}{ Individual level: } \\
\hline T2 Informal social control & 0.045 & 0.010 & 4.54 & 395 & .000 \\
\hline T2 Participation & 0.032 & 0.007 & 4.36 & 395 & .000 \\
\hline T2 Neighboring & 0.034 & 0.010 & 3.51 & 395 & .001 \\
\hline T2 Communitarianism & 0.063 & 0.009 & 6.70 & 395 & .000 \\
\hline T2 Block satisfaction & 0.028 & 0.012 & 2.37 & 395 & .018 \\
\hline T2 Place attachment & 0.098 & 0.017 & 5.77 & 41 & .000 \\
\hline \multicolumn{6}{|c|}{ Cross level interactions (block level predictors interacting with individual-level T2 Place Attachment): } \\
\hline T1 Nonwhite & 0.124 & 0.046 & 2.69 & 41 & .011 \\
\hline $\mathrm{T} 1$ Income & 0.126 & 0.037 & 3.37 & 41 & .002 \\
\hline
\end{tabular}

Final estimation of variance components:

\begin{tabular}{lccccc} 
Random effect & SD & Var. Component & $d f$ & Chi-square & $p$-value \\
\hline INTRCPT, U0 & 0.037 & 0.001 & 38 & 64.42 & .005 \\
T2 Place Attachment & 0.047 & 0.002 & 41 & 68.64 & .005 \\
Level-1, R & 0.155 & 0.024 & & &
\end{tabular}

Level 2 Intraclass $r=.0810, p=.001$ ( $8.1 \%$ of total variance in DV is due to differences between blocks). Model explains over $39 \%$ of Level 1 (individual) variance, and over $68 \%$ of Level 2 (block) variance.

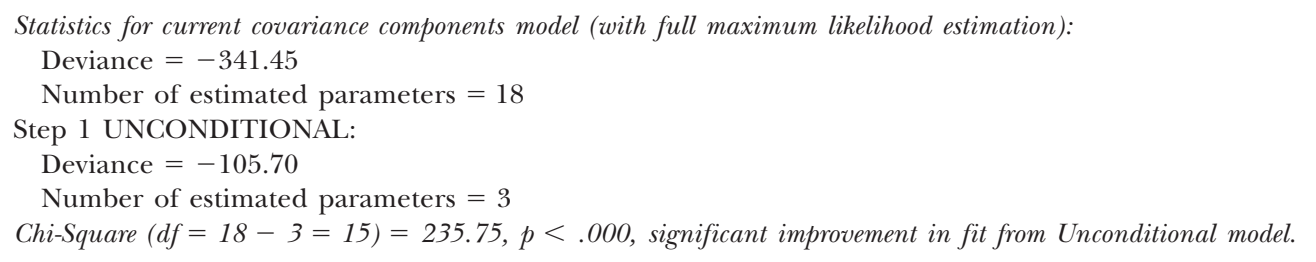




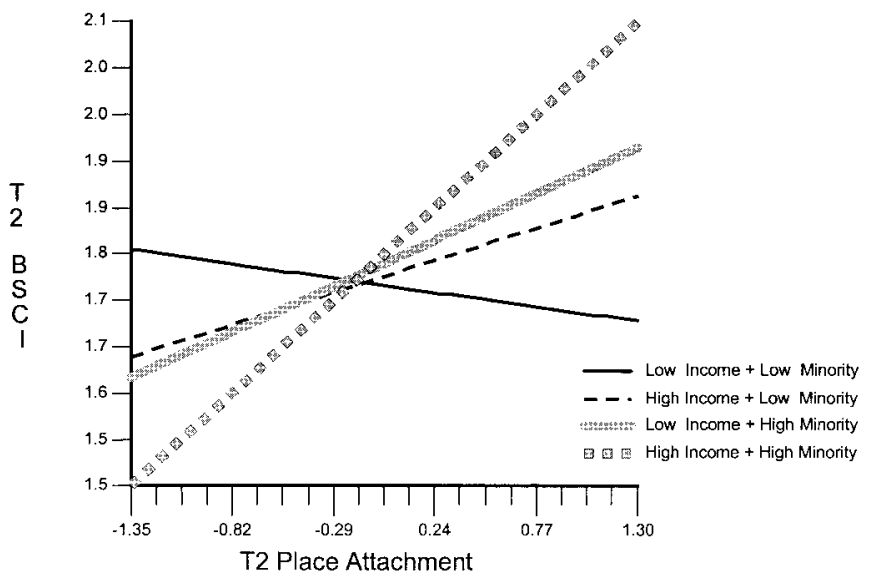

Figure 2. Graph of Cross-level Interactions between Block-level Time 1 Minority (nonwhite) and Income and Individual-level Time 2 Place Attachment Predicting Time 2 Individual-level Sense of Community (BSCI). Note. High and low block-level features indicate averaged upper and lower quartiles within the distribution of these block characteristics.

Charting the cross-level interactions separately showed that $\mathrm{T} 2$ place attachment and T2 BSCI show greater affinity for residents of blocks with higher mean income but also higher proportion nonwhite than for residents of blocks with lower mean income and lower proportion nonwhite (measured at T1). Namely, the positive relation between place attachment and BSCI is enhanced by higher block affluence and nonwhite proportions. However, a more complete and interesting picture of these relations emerges when graphing both block level predictors simultaneously: In Figure 2, high and low block income and high and low block proportion nonwhite (using averaged upper and lower quartiles) are crossed and charted onto the individual relation between place attachment and BSCI (both measured at T2). Only residents of poorer, mostly white blocks showed the contrary slope in which higher place attachment predicted lower BSCI.

Exploratory test of human and social capital interaction. As expected from previous work in SOC, there was no significant main effect for education at either level of analysis when predicting respondent SOC; hence, education was removed (to save statistical power) in the model-building processes predicting T1 and T2 BSCI. Separate HLM models were therefore created to test specifically for individual- and cross-level interaction effects with human capital (education) and social capital (empowerment, neighboring, participation). ${ }^{4}$ For the cross-sectional T1 analyses, no cross-level interaction effects (between respondent-level education and community-level social capital) were significant, although one individual-level interaction was significant. Controlling for education and collective efficacy, as well as nesting of respondents within blocks, the individual-level interaction term Education $\mathrm{X}$ Collective Efficacy was significant

\footnotetext{
${ }^{4}$ Collective efficacy and informal social control were both tested as related components of empowerment. As noted in the methods, however, T2 collective efficacy was not tested due to missing data. Also, appropriate to regression analysis, main effect counterparts to interaction terms were entered into the HLM model for control purposes.
} 


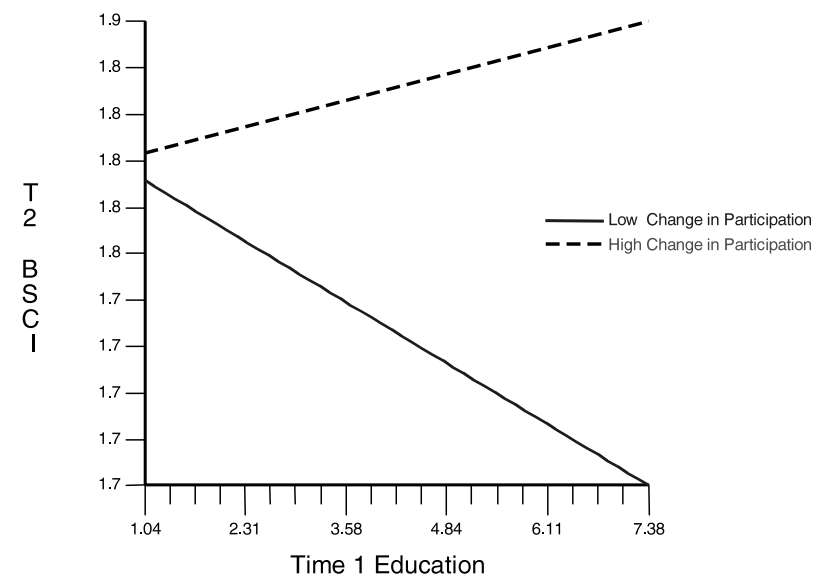

Figure 3. Graph of Cross-level Interaction between Block-level Time Change Civic Participation and Individual-level Time 1 Education Predicting Time 2 Individual-level Sense of Community (BSCI).

Notes: High and low change in block-level participation is the averaged upper and lower quartiles within the distribution. In the sample, roughly as many blocks with participation data at both time points $(\mathrm{N}=$ 44) showed positive change $(n=10)$ as showed no change $(n=9)$, while the majority showed a drop in participation from Time 1 to Time $2(n=25)$. Hence, "low change" here indicates an average of blocks with the highest drop in civic participation over time, while "high change" indicates an average of blocks with the highest rise in participation over time.

$(t(893)=2.88, p=.004)$. The positive coefficient $(0.019)$ for this term suggests education and collective efficacy work in tandem to predict higher SOC.

In analyses predicting T2 BSCI, no significant individual-level interaction effects emerged, although one cross-level interaction term was significant. Controlling for block-level time change participation, T1 respondent education interacted with change in block-level civic participation $(t(42)=1.79, p=.08)$. Figure 3 displays this relation. Individuals with little education (measured at T1) showed equivalent levels of T2 BSCI regardless of the degree or direction of change in participation of the lived-on block. However, the more educated the individual, the more impact change in block participation had in predicting T2 BSCI. Specifically, there is a positive relation between education and BSCI for residents of blocks that show increasing participation levels over time, but there is a negative relation between education and BSCI emerges for residents of blocks showing decreasing civic participation.

\section{DISCUSSION}

This study represents a new, multilevel analysis of the original New York City Block Booster Project data. These data and analyses meet the criteria for obtaining social climate variables from group-aggregated individual responses. As expected from previous multilevel analyses of sense of community (Perkins \& Long, 2002), individuallevel variances were greater than block-level variances. Yet the $5-8 \%$ variance in SOC due to differences between blocks was statistically significant. ${ }^{5}$ Moreover, a high

\footnotetext{
${ }^{5}$ Perkins and Long $(2001,2002)$ reported Intraclass Correlation Coefficients of $9 \%$ and $30 \%$ for T1 and T2 (rather than 5\% and $8 \%$ as reported here; see Erratum in Journal of Community Psychology, 31(4), 2003, p. 435). The former reports were inflated due to missing data for which HLM was unable to correct. The ICCs reported here were calculated using listwise deletion of missing data.
} 
proportion of this within-block agreement of individual-level SOC was explained (68$99 \%$ ) with block-aggregated predictors in multilevel regression analyses.

Individual-level variance in SOC is greater, but less predictable (39\% respondentlevel SOC variance explained in HLM models), although nearly all individual-level social and place-based cognitions and behaviors were significant predictors, most at both time points. Comparing across models, individual-level place attachment was the strongest predictor of SOC, followed by social capital behaviors (neighboring, participation) and perceptions (empowerment, i.e., informal social control and collective efficacy), ${ }^{6}$ as well as communitarianism (which is the value placed on one's community and on working collectively to improve it), and the place-based predictor block satisfaction. Block confidence and length of residence also predicted SOC but only in the $\mathrm{T} 1$ cross-sectional model.

HLM accounts for variance simultaneously at multiple levels (e.g., individuals, groups). Multilevel modeling is thus a useful approach to examining the construct validity of concepts like SOC that are thought to have both individual and communitylevel "climate" properties. Indeed, several of the block-level predictors were significant in predicting respondent-level SOC. Further support for Perkins and Long's (2002) model of social capital was obtained in that block-level empowerment (collective efficacy and informal social control) and neighboring predicted individual SOC (either cross-sectionally or over a 1-year lag), and both block-level civic participation and change in block participation were significant predictors (in separate models). And yet, the most consistently robust social climate predictor of individual SOC was placedbased attachment to the street block. Civic participation and place attachment, the only two block-level predictors significant in both HLM models, were significant only as residualized time change variables in predicting T2 SOC. That is to say, increasing block-level participation and place attachment predicted higher individual SOC at T2, but the absolute level of $\mathrm{T} 1$ participation and place attachment did not significantly predict T2 SOC.

Higher place attachment predicted higher SOC for residents of mostly nonwhite blocks regardless of block affluence and residents of more affluent, mostly white blocks also showed the predicted relation, while residents of poorer, mostly white blocks, on the other hand, showed the contrary effect-higher place attachment predicted lower SOC (see Figure 2). The moderating influence of block affluence is not surprising: Greater resources enable home and community investment, which helps promote place attachment.

The effects for racial climate, however, are more interesting. Elevated community cohesiveness from shared minority identity, perhaps as a shared burden and/or elevated group pride, may explain the enhanced relation between place attachment and SOC for these residents. What is especially interesting about this effect is that it is observed regardless of block-level affluence. Residents of poorer, mostly white blocks, not sharing similar and salient racial identity as well as lacking the shared resources to improve homes and properties, actually exhibited a negative relation between place attachment and SOC. Being attached to one's community as a place may make feelings of social isolation or difference from one's neighbors all the more stark and disappointing.

The exploratory multilevel analyses testing for cross-level interactions of human and social capital in predicting SOC showed a result we found interesting. We used

${ }^{6}$ Individual-level T2 collective efficacy was not tested due to missing data. 
respondent education as a proxy for human capital. For social capital, we used blocklevel empowerment (informal social control and collective efficacy), civic participation, and neighboring. Most of the interaction effects tested were nonsignificant, including all those tested in $\mathrm{T} 1$ cross-sectional analyses. However, an interesting and significant effect emerged when predicting T2 SOC: Individual-level education (measured at T1) interacted with community-level unexpected change in civic participation. Residents with little education showed relatively constant and moderate SOC regardless of the climate change in civic participation of the block community. More education, however, predicted SOC dramatically differently whether residents lived on blocks with increasing or decreasing levels of community participation. Specifically, education and SOC showed a positive relation for residents living on blocks with increasing civic involvement; however, residents of blocks with decreasing participation showed a detriment to SOC with increasing education.

This surprising cross-level effect might be explained in terms of equilibrium of overall human and social capital on the block. Those with more human capital (education) may not need as much informal social capital (sense of community) if their needs are being met via formally organized social capital (block association activity), whereas those with more human capital who live on blocks with decreasing organized participation may be relied on to do more informally and thus develop stronger informal social capital.

It is also interesting that block cohesion for those with less education is unaffected by unexpected change in block participation. Why should only those individuals with more human capital (education) respond to changes in organized social capital around them? We know that individuals with less human capital tend to participate less; whether or not their block's organization is improving or declining may be less important to them, and their level of cohesion is thus unaffected (i.e., for them, there is no positive "free-rider" effect of block organization on sense of community).

The independent and interactive effects of social and place-based cognitions, perceptions, and behaviors, predicted by environmental psychology and presented in Figure 1 were also borne out to some degree. Aspects of the physical environment appear to be as important as the myriad social cues evident in residential communities in shaping individuals' SOC. Indeed, both the respondent-level and the communitylevel place attachment, even when controlling for several social constructs, was the strongest and most reliable predictor of individual-level SOC. ${ }^{7}$ Thus, even after removing the socially derived variance in place-based attachments, this indicator of residential belonging (Altman \& Low, 1992) or place identification (Korpela, 1989; Proshansky et al., 1983; Twigger-Ross \& Uzzell, 1996) was the best overall predictor of residents' SOC with those living on the same street block. Although not as consistently predictive, individual-level block satisfaction and confidence in the future of the street block were also significant predictors of SOC.

When combining multilevel analytical analyses presented here with those of Perkins and Long (2002), qualified multidimensional construct validity of the fourcomponent conceptualization of social capital emerges. As expected, neighboring, participation, and empowerment (collective efficacy and informal social control) are predictive of sense of community cross-sectionally at the individual level. Yet, other

\footnotetext{
${ }^{7}$ This may be partly explained by the place attachment items having come out of the same original scale as most of the BSCI items.
} 
community-focused cognitions (place attachment, communitarianism) are just as predictive. This suggests that the informal-cognitive cell of the model of social capital at the individual level should perhaps be expanded to include more than just sense of community.

There is also mostly good support for the psychological model of social capital (Perkins \& Long, 2002) at the community level. It is impressive that block-level informal social control at $\mathrm{T} 1$ and change in block participation (along with other block level variables) predicted SOC at T2, even after controlling for individual-level predictors. Along with participation, neighboring and collective efficacy were also significant at the block level in the cross-sectional model at T1. However, only 5-8\% of the total variance in SOC is at the block level. Similarly, the block-level variance in collective efficacy is $6 \%$ or $7 \%$ and in neighboring is between $3 \%$ and $7 \%$ (Perkins \& Long, 2002). Among the four components of social capital, only participation has strong variance $(30-40 \%)$ at the block level, which reflects the fact that some blocks are not organized at all and so have no individual-level variation in participation. We do not think this means that most of social capital resides at the individual, psychological level, although that level is clearly important and has been largely ignored by nonpsychologists. It does suggest, however, that social capital works very differently at the community level, that it involves the behavior, power, and resources of whole networks of institutions (Perkins et al., 2002), and that the psychological, sociological, economic, and political perspectives on social capital may be more complimentary than redundant.

\section{REFERENGES}

Ahlbrandt, R.S. (1984). Neighborhoods, people, and community. New York: Plenum Press.

Altman, I., \& Low, S.M. (Eds.). (1992). Place attachment. New York: Plenum Press.

Bennett, S.F., \& Lavrakas, P.J. (1988). A process evaluation of the Eisenhower neighborhood anti-crime self-help Program (Summary Report). Evanston, IL: Center for Urban Affairs and Policy Research.

Brodsky, A.E. (1996). Resilient single mothers in risky neighborhoods: Negative psychological sense of community. Journal of Community Psychology, 24(4), 347-363.

Brodsky, A.E., O'Campo, P.J., \& Aronson, R.E. (1999). PSOC in community context: Multi-level correlates of a measure of psychological sense of community in low-income, urban neighborhoods. Journal of Community Psychology, 27(6), 659-679.

Brown, B.B., \& Perkins, D.D. (1992). Disruptions in place attachment. Human Behavior and Environment: Advances in Theory and Research, 12, 279-304.

Brown, B.B., \& Werner, C.M. (1985). Social cohesiveness, territoriality, and holiday decorations: The influence of cul-de-sacs. Environment and Behavior, 17(5), 539-565.

Bryk, A.S., \& Raudenbush, S.W. (1992). Hierarchical linear models: Applications and data analysis methods. Newbury Park: Sage Publications.

Buckner, J.C. (1988). The development of an instrument to measure neighborhood cohesion. American Journal of Community Psychology, 16(6), 771-791.

Chavis, D.M., \& Pretty, G.M.H. (1999). Sense of community: Advances in measurement and application. Journal of Community Psychology, 27(6), 635-642.

Chavis, D.M., \& Wandersman, A. (1990). Sense of community in the urban environment: A catalyst for participation and community development. American Journal of Community Psychology, 18(1), 55-81. 
DeLisi, M., \& Regoli, B. (2000). Individual neighborhood attachment and perceptions of neighborhood safety. American Journal of Criminal Justice, 24(2), 181-188.

Fischer, C.S. (1977). Networks and places: Social relations in the urban setting. New York: Free Press.

Fisher, A.T., Sonn, C.C., \& Bishop, B.J. (Eds.). (2002). Psychological sense of community: Research, applications, and implications. New York: Kluwer Academic/Plenum Publishers.

Gotham, K.F. (1999). Political opportunity, community identity, and the emergence of a local anti-expressway movement. Social Problems, 46(3), 332-354.

Hill, J.L. (1996). Psychological sense of community: Suggestions for future research. Journal of Community Psychology, 24(4), 431-438.

Hughey, J., Speer, P.W., \& Peterson, N.A. (1999). Sense of community in community organizations: Structure and evidence of validity. Journal of Community Psychology, 27(1), 97-113.

Hyde, M.M. (1998). Local sentiments in urban neighborhoods: Multilevel models of sense of community and attachment to place. Unpublished doctoral dissertation, University of Maryland-Baltimore County.

Itzhaky, H., \& York, A.S. (2000). Sociopolitical control and empowerment: An extended replication. Journal of Community Psychology, 28(4), 407-415.

Kingston, S., Mitchell, R., Florin, P., \& Stevenson, J. (1999). Sense of community in neighborhoods as a multi-level construct. Journal of Community Psychology, 27, 681-694.

Korpela, K.M. (1989). Place-identity as a product of environmental self-regulation. Journal of Environmental Psychology, 9(3), 241-256.

Long, D.A., \& Perkins, D.D. (2003). Confirmatory factor analysis of the Sense of Community Index and development of a Brief SCI. Journal of Community Psychology, 31(3), 279-296.

McMillan, D.W., \& Chavis, D.M. (1986). Sense of community: A definition and theory. Journal of Community Psychology, 14(1), 6-23.

Perkins, D.D., Brown, B.B., \& Taylor, R.B. (1996). The ecology of empowerment: Predicting participation in community organizations. Journal of Social Issues, 52(1), 85-110.

Perkins, D.D., Florin, P., Rich, R.C., Wandersman, A., \& Chavis, D.M. (1990). Participation and the social and physical environment of residential blocks: Crime and community context. American Journal of Community Psychology, 18(1), 83-115.

Perkins, D.D., Hughey, J., \& Speer, P.W. (2002). Community psychology perspectives on social capital theory and community development practice. Journal of the Community Development Society, 33(1), 33-52.

Perkins, D.D., \& Long, D.A. (2001, June). Neighborhood sense of community and social capital: "All the things you are." Paper presented at the Biennial Conference on Community Research \& Action, Atlanta, GA.

Perkins, D.D., \& Long, D.A. (2002). Neighborhood sense of community and social capital: A multi-level analysis. In A.T. Fisher \& C.C. Sonn (Eds.), Psychological sense of community: Research, applications, and implications (pp. 291-318). New York: Kluwer Academic/ Plenum Publishers.

Perkins, D.D., Wandersman, A.H., Rich, R.C., \& Taylor, R.B. (1993). The physical environment of street crime: Defensible space, territoriality and incivilities. Journal of Environmental Psychology, 13(1), 29-49.

Pretty, G.M.H. (2002). Young people's development of the community-minded self: Considering community identity, community attachment and sense of community. In A.T. Fisher \& C.C. Sonn (Eds.), Psychological sense of community: Research, applications, and implications (pp. 183-203). New York: Kluwer Academic/Plenum Publishers.

Prezza, M., Amici, M., Roberti, T., \& Tedeschi, G. (2001). Sense of community referred to the whole town: Its relations with neighboring, loneliness, life satisfaction, and area of residence. Journal of Community Psychology, 29(1), 29-52. 
Proshansky, H.M., Fabian, A.K., \& Kaminoff, R. (1983). Place-identity: Physical world socialization of the self. Journal of Environmental Psychology, 3(1), 57-83.

Puddifoot, J.E. (1996). Some initial considerations in the measurement of community identity. Journal of Community Psychology, 24(4), 327-336.

Puddifoot, J.E. (1997). Psychological reaction to perceived erasure of community boundaries. Journal of Social Psychology, 137(3), 343-355.

Sampson, R.J. (1991). Linking the micro- and macrolevel dimensions of community social organization. Social Forces, 70(1), 43-64.

Sampson, R.J., Raudenbush, S.W., \& Earls, F. (1997). Neighborhoods and violent crime: A multilevel study of collective efficacy. Science, 277(5328), 918-924.

Sarason, S.B. (1974). The psychological sense of community: Prospects for a community psychology. Cambridge, MA: Brookline Books.

Shumaker, S.A., \& Taylor, R.B. (1983). Toward a clarification of people-place relationships. In N.R. Feimer \& E.S. Geller (Eds.), Environmental psychology: Directions and perspectives (p. 356). New York: Praeger.

Speer, P.W. (2000). Intrapersonal and interactional empowerment: Implications for theory. Journal of Community Psychology, 28(1), 51-61.

Tajfel, H., \& Turner, J.C. (1979). An integrative theory of intergroup relations. In W.G. Austin \& S. Worchel (Eds.), The social psychology of intergroup relations (pp. 33-48). Monterey, CA: Brooks/Cole.

Taylor, R.B. (1996). Neighborhood responses to disorder and local attachments: The systemic model of attachment, social disorganization, and neighborhood use value. Sociological Forum, 11(1), 41-74.

Tuan, Y.-f. (1974). Topophilia: A study of environmental perception, attitudes, and values. Englewood Cliffs, NJ: Prentice-Hall.

Twigger-Ross, C.L., \& Uzzell, D.L. (1996). Place and identity processes. Journal of Environmental Psychology, 16(3), 205-220.

Unger, D.G., \& Wandersman, A. (1985). The importance of neighbors: The social, cognitive, and affective components of neighboring. American Journal of Community Psychology, 13(2), $139-169$.

Varady, D.P. (1986). Neighborhood confidence: A critical factor in neighborhood revitalization? Environment and Behavior, 18(4), 480-501.

Wandersman, A., \& Giamartino, G.A. (1980). Community and individual difference characteristics as influences on initial participation. American Journal of Community Psychology, 8(2), 217-228. 